\title{
A Study on Testing Concrete Strength by Inversely Regressed \\ Synthesis Ultrasonic-rebound Method
}

\author{
Wantong Cai ${ }^{1, a}$, Guoping Cen ${ }^{1, b}$, Wenzhe $\mathrm{Li}^{1, \mathrm{c}}$, Bo Fan $^{1, \mathrm{~d}}$ \\ ${ }^{1}$ Air Force Engineering University \\ awantong15@126.com, ${ }^{b} 416992607 @ q q . c o m,{ }^{c} 172046386 @ q q . c o m,{ }^{d}$ fanbo81@163.com
}

\begin{abstract}
Keywords:Ultrasonic method; Rebound method; Data fusion; Strength-measuring curve; Nondestructive testing of concrete
\end{abstract}

Abstract:Ultrasonic-rebound combined method (UCM) is widely adopted to test concrete strength at present. Although it makes up for some shortcomings of rebound method and ultrasonic method respectively, its precision is far below the requirements of engineering. Based on the thought data fusion and inverse regression model, this paper puts forward inversely regressed synthesis ultrasonic-rebound method (IRSUM). By combining rebound method and ultrasonic method to conduct strength testing and applying data fusion method of unequal precision measurement in inverse regression problems to data processing, this paper finds a new method of IRSUM to do nondestructive testing of concrete strength. Also, IRSUM and UCM is adopted to calculate the strength of five groups, C15, C20, C30, C40 and C50, which include 90 test specimens. Then it is compared with the actual compressive strength of the test specimens, and the author finds the result of IRSUM is more close to the actual strength value than that of UCM. IRSUM can evidently increase the precision of nondestructive testing of concrete strength as the average value of relative error's absolute value reduces $63 \%$ and the variance of relative error's absolute value reduces $80 \%$. Besides, the method of this paper can be extended to data fusion problems of measuring values with different dimensions.

\section{Introduction}

For a long period, people evaluate concrete strength according to the compressive strength of standard test specimen, but it has been questioned to take the quality of test specimen as the real quality of structural concrete. People attach more and more significance on the real strength of structural concrete on construction site. However, direct testing of concrete strength on structural concrete can't do without nondestructive testing technology [1].

NDT technology is to use certain apparatus to acquire some physical quantities (rebound value, sound velocity [2], withdrawal force, etc) of constructions or components directly. By establishing relation curve (strengthmeasuring curve) between certain physical quantity and strength of test specimen in advance, people can get the data of concrete strength and presume the structural strength. Due to numerous uncertain factors [3], the measured values (rebound value, ultrasonic value, etc) are distributed which brings low precision and large uncertainty and leads to difficulties in engineering application.

Presently many researches raise multi means to enhance the precision of concrete nondestructive testing [4-10]. UCM is a widely recognized method now in engineering [11] and it improves rebound method and ultrasonic method to some extent. But as it is far beyond the reach of engineering requirements, the results can only be used as reference value.

On account of the engineering requirements of improving testing precision and based on the thought of data fusion and inverse regression model, this paper puts forward IRSUM, a method to test structural concrete strength. 
The testing results are processed by means of inverse regression fusion of testing results given by different test methods. The experimental data indicates this method improves test precision.

\section{Materials and Methods}

\section{Preparation and experiment}

According to the design requirements of experiment, test specimens are made in a representative concrete batching plant in Xi'an. Cement is the kind of $42.5 \mathrm{R}$, local medium sand is used as fine aggregate, and limestone rubble is the coarse aggregate (the maximum particle size is $31.5 \mathrm{~mm}$ ). Mixture is hand tamped after mechanical agitation and the test cube $(150 \mathrm{~mm} * 150 \mathrm{~mm} * 150 \mathrm{~mm})$ is made in terms of standard test method.

Based on JGJ/T 23-2002 Technical Regulations of Testing Concrete Compressive Strength Using Rebound Method, the author flicks the two relative test surface using rebound apparatus in 8 dots, removes the three maximum values and three minimum values from the total 16 values, and then takes the average of the remaining ten values as $R$. Relative test surface which is the same with rebound test surface is chosen to layout three test dots and the axes of launching and receiving transducer of ultrasonic detecting instrument is set in the same axis. The average of sound velocity of three times is taken as ${ }^{v}$ [12]. Vernier caliper is used to measure the depth value of concrete carbonation $l$ and compressive destruction test is conducted to get compressive strength value $f$. The results arrive at different strength grades including C10, C15, C20, C30, C40 and C50, different curing ages of $14 \mathrm{~d}, 28 \mathrm{~d}, 60 \mathrm{~d}, 90 \mathrm{~d}$ and $180 \mathrm{~d}$ and test values of 212 groups of test specimen.

\section{Regression model}

In concrete nondestructive testing, the rebound value and sound velocity in the same test area is measurement quantity of equal precision, but the strength values got by the strength-measuring curve of rebound method and sound velocity method respectively is of unequal precision.

In the process of regression, dependent variables are always assumed to be random variables while predictor variables are not randomly changed. Only when independent variables are less random and dependent variables are more random can the error of using least square method be smaller. Otherwise $\sigma_{j}^{2}$ is inaccurate and weight estimation of fusion expression in accurate as well which will result in big deviation in ultimate estimated value.

The frequent regression equation of rebound method is $f=A_{1} \cdot R^{B_{1}} \cdot 10^{C_{1} \cdot l}$. In real test, due to the own property of rebound apparatus, surface condition of test specimen, carbonation depth of concrete and technological level of operating staff, rebound value $R$ has large randomness. Under standard test method, the compressive strength value of test specimen is less random than rebound value which is contradict to the premise of using least square method and then leads to big error.

Thus, this study adopts a new regression model which exchanges independent variable $R$ and dependent variable $f$ in traditional regression equation. So the equation becomes $R=a_{1} \cdot f^{b_{1}} \cdot 10^{c_{1} \cdot l}$. While employing new strength-measuring curve to estimate strength value, inverse regression (inverse prediction) should be adopted. 


\section{Inverse regression data fusion}

Based on [13-16], it can be concluded that the essence of data fusion of unequal measure of precision is a weighted sum and it can be described by the following expression:

$$
W=\sum_{j=1}^{n} r_{j} P_{j}
$$

$W$ is the estimated value being measured, ${ }^{r}$ is weight and ${ }^{P_{j}}$ is the estimated value that is measured by the method of ${ }^{j}$ times. When the precision of the method is low (variance is large), weight should be small to raise test accuracy.

After ultrasonic method and rebound method are used, strength-measuring curve of inverse regression for each method is made. Then logarithmic strength values are acquired according to each curve. By fusing the value of the same test area, the author takes the inverse natural logarithm and gets the strength value of test concrete.

Establishment of single-method strength-measuring curve

Rebound method

The relation between rebound value and strength can be described as non-linear relationship. By variable transformation, it can be transferred to linear problem.

Strength-measuring curve of regular rebound method:

$$
f=A_{1} \cdot R^{B_{1}} \cdot 10^{C_{1} \cdot l}
$$

Strength-measuring curve obtained by inverse regression:

$$
R=a_{1} \cdot f^{b_{1}} \cdot 10^{c_{1} \cdot l}
$$

$f \_$compressive strength value of test concrete specimen

$R \_$rebound value of test specimen

$l \_$__arbonation depth of test specimen

$a_{1}, b_{1}, c_{1} \_$undetermined coefficient which will be determined by least square method

$$
y_{1}=\ln R, \beta_{10}=\ln a_{1}, \beta_{11}=b_{1}
$$

Take natural logarithm of each side, make $d_{1}=\ln f, \beta_{12}=c_{1} \cdot \ln 10, d_{2}=l$, and we can get equation of linear regression:

$$
y_{1}=\beta_{10}+\beta_{11} d_{1}+\beta_{12} d_{2}
$$

The above equation can be used to conduct regression analysis using least square method.

Ultrasonic method

Strength-measuring curve of regular ultrasonic method:

$$
f=A_{2} \cdot v^{B_{2}}
$$

Strength-measuring curve obtained by inverse regression: 


$$
v=a_{2} \cdot f^{b_{2}}
$$

$f \_$compressive strength value of test concrete specimen

$v \_$_ sound velocity of test specimen

$a_{2}, b_{2}$ undetermined coefficient

Take natural logarithm of each side, make $y_{2}=\ln v, \beta_{20}=\ln a_{2}, \beta_{21}=b_{2}, x=\ln f$, the original equation becomes:

$$
y_{2}=\beta_{20}+\beta_{21} x
$$

Least square method can be used to calculate regression coefficient. Calculating logarithmic strength value using inverse prediction

Take rebound value of given test area as $R_{h}$ and carbonized depth value as $l_{h}$, and the corresponding logarithmic strength value $y_{1 h}=\ln R_{h}$, corresponding strength value in rebound method area $x_{11 h}=\ln f_{R h}$. From equation (1), we can get:

$$
\hat{x}_{11 h}=\frac{y_{1 h}-\hat{\beta}_{12} x_{2 h}-\hat{\beta}_{10}}{\hat{\beta}_{11}}
$$

That is:

$$
\ln \hat{f}_{R h}=\frac{\ln R_{h}-\hat{\beta}_{12} \cdot l_{h}-\hat{\beta}_{10}}{\hat{\beta}_{11}}
$$

Give the sound velocity $v_{h}$, then the corresponding logarithmic sound velocity value $y_{2 h}=\ln v_{h}$ and the corresponding logarithmic strength value in ultrasonic method area $x_{21 h}=\ln f_{v h}$ :

$$
\hat{x}_{21 h}=\frac{y_{2 h}-\hat{\beta}_{20}}{\hat{\beta}_{21}}
$$

That is:

$$
\ln \hat{f}_{v h}=\frac{\ln v_{h}-\hat{\beta}_{20}}{\hat{\beta}_{21}}
$$

IRSUM equation to test strength

For given $R_{h}, l_{h}$, and $v_{h}$, the logarithmic strength value after fusion $x_{1 h}=\ln f_{h}$ can be demonstrated as follows:

$$
\hat{x}_{1 h}=r_{1} \hat{x}_{11 h}+r_{2} \hat{x}_{21 h}
$$


That is:

$$
\ln \hat{f}_{h}=r_{1} \cdot \ln \hat{f}_{R h}+r_{2} \cdot \ln \hat{f}_{v h}
$$

$$
r_{1}=\frac{\frac{\hat{\beta}_{11}^{2}}{\hat{\sigma}_{1}^{2}}}{\frac{\hat{\beta}_{11}^{2}}{\hat{\sigma}_{1}^{2}}+\frac{\hat{\beta}_{21}^{2}}{\hat{\sigma}_{2}^{2}}}, r_{2}=\frac{\frac{\hat{\beta}_{21}^{2}}{\hat{\sigma}_{2}^{2}}}{\frac{\hat{\beta}_{11}^{2}}{\hat{\sigma}_{1}^{2}}+\frac{\hat{\beta}_{21}^{2}}{\hat{\sigma}_{2}^{2}}}, \hat{f}_{h}=\exp \left(\ln \hat{x}_{1 h}\right)
$$

\section{Results and Discussion}

The truth value of undetermined coefficient in equation (12) and (13) can be obtained by least square method and then it can be used to calculate ${ }^{\hat{r}_{1}}$ and $\hat{r}_{2}$. It is demonstrated in Table 1.

Table 1 Computation of undetermined coefficient

\begin{tabular}{|c|c|c|c|c|c|c|c|c|}
\hline$\hat{\beta}_{12} x_{2 h}$ & $\hat{\beta}_{11}$ & $\hat{\beta}_{10}$ & $\hat{\sigma}_{1}^{2}$ & $\hat{\beta}_{20}$ & $\hat{\beta}_{21}$ & $\hat{\sigma}_{2}^{2}$ & $r_{1}$ & $r_{2}$ \\
\hline 1.53319 & 0.56661 & 0.04605 & 0.0012 & 1.15033 & 0.10797 & 0.00077 & 0.91896 & 0.08104 \\
\hline
\end{tabular}

Put the above results in equation (13), we can get the strength-measuring equation of IRSUM:

$$
\ln \hat{f}_{h}=1.62186 \cdot \ln R_{h}+0.75058 \cdot \ln v_{h}-0.07469 l_{h}-3.35006
$$

That is:

$$
\hat{f}_{h}=0.03508 v_{h}^{0.75058} R_{h}^{1.62186} e^{-0.07469 l_{h}}
$$

In order to examine the effect of this equation, the author makes a group of 30 test specimens using the same method, and then conduct measurement of rebound, ultrasonic, carbonation depth and compression test. The data is listed in Table 2.

Table 2 Rebound value, ultrasonic value, carbonation depth and compressive strength data

\begin{tabular}{|c|c|c|c|c|}
\hline Serial number & Rebound value & $\begin{array}{c}\text { Ultrasonic } \\
\text { value }\end{array}$ & $\begin{array}{c}\text { Carbonization } \\
\text { depth }\end{array}$ & $\begin{array}{c}\text { Compressive } \\
\text { strength }\end{array}$ \\
\hline 1 & 44.3 & 4.62 & 3.5 & 38.2 \\
\hline 2 & 45.0 & 4.7 & 6.0 & 33.0 \\
\hline 3 & 43.4 & 4.6 & 3.5 & 39.6 \\
\hline 4 & 42.5 & 4.56 & 3.5 & 36.7 \\
\hline 5 & 42.4 & 4.63 & 3.5 & 36.8 \\
\hline 6 & 43.7 & 4.57 & 4.0 & 35.6 \\
\hline 7 & 48.2 & 4.59 & 4.5 & 43.6 \\
\hline 8 & 46.3 & 4.73 & 3.5 & 43.3 \\
\hline 9 & 48.3 & 4.75 & 5.5 & 40.3 \\
\hline 10 & 45.1 & 4.75 & 4.0 & 39.3 \\
\hline 11 & 49.4 & 4.75 & 6.0 & 40.1 \\
\hline 12 & 48.6 & 4.69 & 3.5 & 43.9 \\
\hline 13 & 50.4 & 4.95 & 4.0 & 47.6 \\
\hline 14 & 49.7 & 4.89 & 3.5 & 50.2 \\
\hline 15 & 49.7 & 4.93 & 1.5 & 54.2 \\
\hline 16 & 48.9 & 4.85 & 2.5 & 48.7 \\
\hline 17 & 52.7 & 4.89 & 4.5 & 50.0 \\
\hline 18 & 49.8 & 4.92 & 3.0 & 50.7 \\
\hline
\end{tabular}




\begin{tabular}{|l|l|l|l|l|}
\hline 19 & 52.9 & 4.93 & 3.5 & 51.3 \\
\hline 20 & 51.6 & 4.92 & 3.0 & 52.9 \\
\hline 21 & 52.0 & 4.92 & 3.5 & 56.4 \\
\hline 22 & 52.0 & 4.93 & 6.0 & 46.2 \\
\hline 23 & 51.9 & 4.90 & 5.5 & 45.2 \\
\hline 24 & 50.8 & 4.78 & 4.5 & 48.2 \\
\hline 25 & 52.3 & 5.08 & 1.5 & 59.6 \\
\hline 26 & 52.1 & 5.19 & 0.5 & 66.7 \\
\hline 27 & 53.7 & 5.10 & 2.0 & 59.1 \\
\hline 28 & 53.2 & 5.14 & 1.0 & 61.1 \\
\hline 29 & 52.8 & 5.14 & 1.5 & 60.2 \\
\hline 30 & 50.1 & 5.10 & 0.5 & 58.0 \\
\hline
\end{tabular}

The author compares the compressive strength value arrived by IRSUM, that obtained by UCM and the actual value of test specimen and demonstrates the results in Table 3 and Figure 1. The average of relative error's absolute value of this method and UCM and the variance is described in Table 4. The relative error's absolute value comparison between the two methods and the real value can be seen in Figure 2.

Table 3 Comparison between this method and UCM

\begin{tabular}{|c|c|c|c|}
\hline Serial number & Tested values & IRSUM & $\mathrm{UCM}$ \\
\hline 1 & 38.2 & 39.87 & 42.85 \\
\hline 2 & 33.0 & 34.37 & 45.03 \\
\hline 3 & 39.6 & 38.44 & 41.39 \\
\hline 4 & 36.7 & 36.91 & 39.67 \\
\hline 5 & 36.8 & 37.20 & 40.57 \\
\hline 6 & 35.6 & 37.27 & 41.32 \\
\hline 7 & 43.6 & 42.22 & 47.43 \\
\hline 8 & 43.3 & 43.60 & 47.28 \\
\hline 9 & 40.3 & 40.34 & 50.37 \\
\hline 10 & 39.3 & 40.37 & 45.98 \\
\hline 11 & 40.1 & 40.31 & 51.91 \\
\hline 12 & 43.9 & 46.86 & 49.72 \\
\hline 13 & 47.6 & 49.87 & 57.13 \\
\hline 14 & 50.2 & 50.14 & 54.94 \\
\hline 15 & 54.2 & 58.58 & 55.69 \\
\hline 16 & 48.7 & 52.30 & 53.03 \\
\hline 17 & 50.0 & 51.17 & 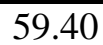 \\
\hline 18 & 50.7 & 52.46 & 55.65 \\
\hline 19 & 51.3 & 55.82 & 60.52 \\
\hline 20 & 52.9 & 55.57 & 58.35 \\
\hline 21 & 56.4 & 54.21 & 58.95 \\
\hline 22 & 46.2 & 45.04 & $\overline{59.15}$ \\
\hline 23 & 45.2 & 46.40 & 58.40 \\
\hline 24 & 48.2 & 47.40 & 54.45 \\
\hline 25 & 59.6 & 65.08 & 62.68 \\
\hline 26 & 66.7 & 70.82 & 64.64 \\
\hline 27 & 59.1 & 65.63 & 65.35 \\
\hline 28 & 61.1 & 70.06 & 65.40 \\
\hline 29 & 60.2 & 66.67 & 64.74 \\
\hline 30 & 58.0 & 65.59 & 59.58 \\
\hline
\end{tabular}




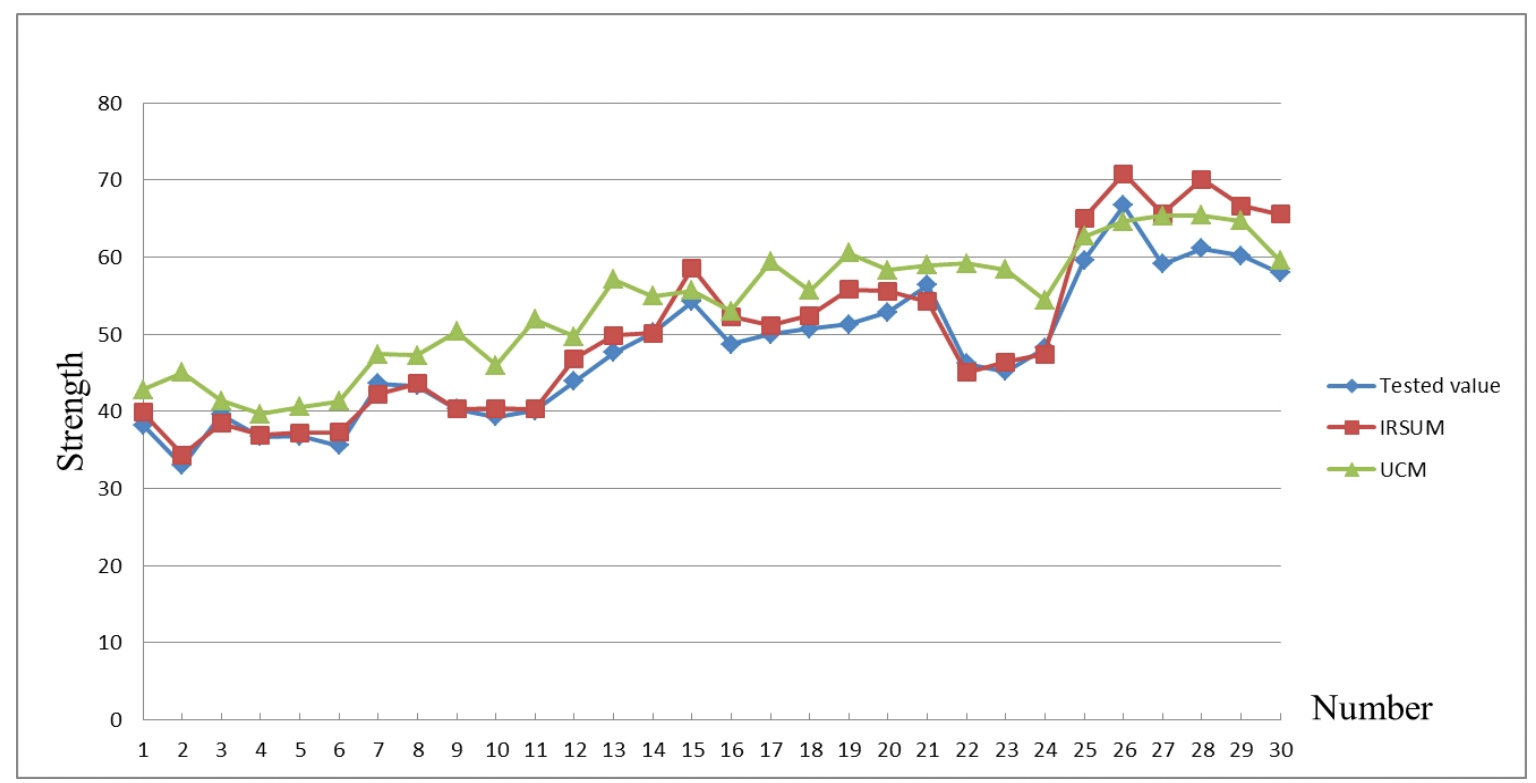

Fig. 1 Prediction curves of IRSUM and UCM

The experiment shows that the result of this method is closer to the real compressive strength value compared with UCM. The mean value and variance of relative error's absolute value respectively reduced $63 \%$ and $80 \%$ (see Table 4 ).

Table 4 Comparison between the two methods in means and variances of relative error's absolute value

\begin{tabular}{|c|c|c|}
\hline Method & $\begin{array}{c}\text { Means of relative error's } \\
\text { absolute value }\end{array}$ & $\begin{array}{c}\text { Variances of relative } \\
\text { error's absolute value }\end{array}$ \\
\hline IRSUM & 0.04913353 & 0.00154892 \\
\hline UCM & 0.133006933 & 0.007863929 \\
\hline Error reduction ratio/\% & 63 & 80 \\
\hline
\end{tabular}

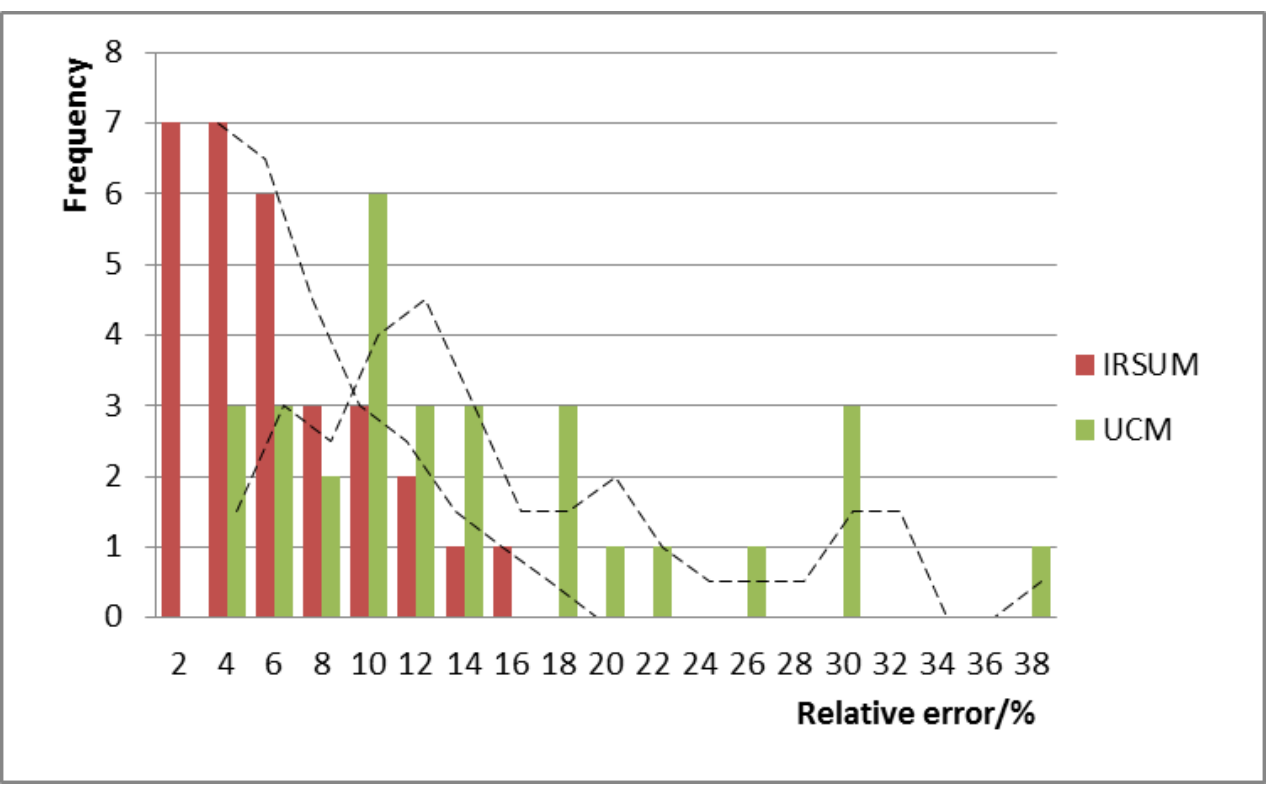

Fig. 2 Distribution of relative error's absolute value 


\section{Conclusions}

(1) The formula of IRSUM to test concrete strength is given. This method conducts point estimation of indirect measurement value using multi specimen of different variances, and then according to inverse regression method and maximum likelihood theory, this method does effective fusion of estimated values (rebound value and sound velocity value) of different dimensions to evaluate the strength value of test concrete. A theoretic analysis indicates that the result is unbiased and of least variance.

(2) The processing result of experimental data shows this method has a high precision in testing concrete strength compared with UCM. The relative error's absolute value mean and variance of strength estimated value arrived by this method is respectively $63 \%$ and $80 \%$ lower than traditional methods.

(3) This method can be used to do data fusion of measuring values with different dimensions which are obtained by different test instrument. By estimating measured values, this method can reduce system error and random error effectively. Instead of being restricted to data processing of concrete strength nondestructive testing, this method also applies to similar problems in such areas as medicine and economics.

(4) This method is only proved to be of high precision by data in the lab. For its real application effect in field test, there should be more test data in the field.

\section{References}

[1]. Kozlov, A.V., Kozlov, V.N., The development and current state of methods for the nondestructive testing and acoustic tomography of concrete, Rus. J. Nondestruct. Test., 2015, vol. 51, no. 6, pp. 329-337.

[2]. Brigante, M., Sumbatyan, M.A., Acoustic methods in nondestructive testing of concrete: Review of foreign publications in the field of theoretical studies, Rus. J. Nondestruct. Test., 2013, vol. 49, no. 4, pp. 185-195.

[3]. Kartashev, V.G., Kachanov, V.K., and Sokolov, I.V., Application of synchronous detection for ultrasonic thickness gauging of concrete Articles with a nonuniform Structure, Rus. J. Nondestruct. Test., 2015, vol. 51, no. 8, 486-496.

[4]. Breysse, D., Nondestructive evaluation of concrete strength: An historical review and a new perspective by combining NDT methods, Constr. Build. Mater., 2012, vol. 33, pp. 139-163.

[5]. Selcuk, L., Nar, A., Prediction of uniaxial compressive strength of intact rocks using ultrasonic pulse velocity and rebound-hammer number, Q. J. Eng. Geol. Hydrogeol. 2016, vol. 49, no. 1, pp. 67-75.

[6]. Huang, Q.D., Gardoni, P., and Hurlebaus, S., Predicting Concrete Compressive Strength Using Ultrasonic Pulse Velocity and Rebound Number, ACI. Mater. J., 2011, vol. 108, no. 4, 403-412.

[7]. Ismail, Z., Ibrahim, Z., and Ong, AZC., Approach to Reduce the Limitations of Modal Identification in Damage Detection Using Limited Field Data for Nondestructive Structural Health Monitoring of a Cable-Stayed Concrete Bridge, J. Bridg. Eng., 2012, vol. 17, no. 6, pp. 867-875.

[8]. Fursa, T.V., Dann, D.D., and Demikhova, A.A., A Scanner for the Detection of Defective Areas in Large Concrete Products, Rus. J. Nondestruct. Test., 2015, vol. 51, no. 7, pp. 428-432.

[9]. Pazdera, L., Topolar, L., Application acoustic emission method during concrete frost resistance, Rus. J. Nondestruct. Test., 2014, vol. 50, no. 2, pp. 127-131.

[10]. Shang, H.S., Yi, T.H., and Yang, L.S., Experimental Study on the Compressive Strength of Big Mobility Concrete with Nondestructive Testing Method, Adv. Mater. Sci. Eng., 2012, vol. 45, pp. 1- 
6.

[11]. Rong, H., Qian, C.X., and Gao L.X., The Testing Strength Curves of Lightweight Aggregate Concrete by Rebound Method and Ultrasonic-rebound Combined Method, J. Wuhan. Univ. Technol., 2011, vol. 26, no. 5, pp. 1010-1017.

[12]. Fursa, T.V., Osipov, K.Y., and Dann, D.D., Development of a Nondestructive Method for Testing the Strength of Concrete with a Faulted Structure Based on the Phenomenon of Mechanoelectric Transformations, Rus. J. Nondestruct. Test., 2011, vol. 47, no. 5, pp. 323-328.

[13]. BUNGEY, J.H., The Testing of Concrete in Structures. Senior Lecture in Civil Engineering University of Liverpool.Surney University Press, 1989, vol. 46.

[14]. Carino, N.J.. Nondestructive Testing of Concrete: History and Challenges. Concrete Technology-Past, Present and Future, P. K. Mehta, Ed., American Concrete Institute, Detroit, MI, 1994, pp. 623-678.

[15]. John Neter William Wasserman Michael H•Kutner. Applied Linear Regression Models. RICHARD D. IRWIN. INC., 1983, pp. 243-284.

[16]. John Neter William Wasserman Michael H•Kutner. Applied Linear Regression Models. RICHARD D. IRWIN. INC., 1983, pp. 21-52. 